\title{
Enhanced rules-of-mixture for natural fibre reinforced polymer matrix (NFRP) composites (comment on Lau et al in volume 136)
}

Summerscales, John

http://hdl.handle.net/10026.1/12480

10.1016/j.compositesb.2018.10.021

Composites Part B: Engineering

Elsevier

All content in PEARL is protected by copyright law. Author manuscripts are made available in accordance with publisher policies. Please cite only the published version using the details provided on the item record or document. In the absence of an open licence (e.g. Creative Commons), permissions for further reuse of content should be sought from the publisher or author. 
Type of paper: Letter commenting on a recently published paper

\title{
Enhanced rules-of-mixture for natural fibre reinforced polymer matrix (NFRP) composites (comment on Lau et al in volume 136)
}

\author{
John Summerscales ${ }^{1, *}$, Amandeep Singh Virk ${ }^{2}$ and Wayne Hall ${ }^{3}$ \\ ${ }^{1}$ MAterials and STructures (MAST) Research Group/Composites Engineering, \\ School of Engineering, University of Plymouth, Plymouth PL4 8AA, United Kingdom. \\ ${ }^{2}$ Metalboss Technologies Inc., 12948170 St NW, Edmonton, Alberta T5V 0B4, Canada. \\ ${ }^{3}$ Griffith School of Engineering, Gold Coast campus, \\ Griffith University, Queensland 4222, Australia. \\ * Corresponding author: e-mail: jsummerscales@plymouth.ac.uk, T: +44 1752586150
}

Keywords: natural fibre; rules-of-mixture; fibre area correction factor

\begin{abstract}
The use of rules-of-mixture to predict the elastic modulus and strength of natural fibre-reinforced composites is often compromised by the fibre properties used in the calculations being derived with an assumption of circular cross-section, when real fibres have polygonal cross-section. A fibre area correction factor (FACF) has been proposed to address this inaccuracy and has been demonstrated to improve the predictions.
\end{abstract}

Letter: Lau et al [1] have stated that "it is challenging to develop a generic formula to predict the structural and mechanical properties of NFRP [natural fibre reinforced polymer matrix] composites" and that the traditional shear-lag "model is not applicable to NFRP composites due to the imperfect shape of nature fibres along their longitudinal direction and irregular shape of fibres' cross section".

Virk et al [2] (the authors of this letter) introduced a "fibre area correction factor (FACF)" to address this issue in the context of the rules-of-mixture (RoM) for natural fibre reinforced composites. The FACF, denoted $\kappa$, is determined as the ratio of the apparent fibre cross-section area (CSA) divided by the true fibre CSA for a set of observations. While it is impractical to determine this value for each individual fibre test, a sensible $\kappa$ value can be determined from the mean values for a set of measurements using "apparent diameters" (obtained prior to experimental fibre tests), and by measuring the true fibre polygonal CSA from polished fibres/composites mounted parallel to the microscope axis, respectively.

The modified RoM [2] become Equation (1) for elastic modulus of any composite, and Equation (2) for strength (limited to quasi-unidirectional composites) by extending the KellyTyson model [3]:

$$
\begin{aligned}
& E_{c}=\kappa \eta_{d} \eta_{1} \eta_{o} E_{f} V_{f}+E_{m} V_{m} \\
& \sigma^{\prime}{ }_{c}=\kappa \sigma_{f}^{\prime} V_{f}+\sigma^{*}{ }_{m} V_{m}
\end{aligned}
$$

where $\mathrm{E}=$ elastic modulus, $\eta_{\mathrm{d}}=$ fibre diameter distribution factor, $\eta_{1}=$ fibre length distribution factor, $\eta_{\mathrm{o}}=$ fibre orientation distribution factor, $\mathrm{V}_{\mathrm{f}}=$ component volume fraction, $\sigma^{\prime}=$ strength, $\sigma^{*}{ }_{m}=$ stress in the matrix at the failure strain of the fibre, and subscripts $\mathrm{c}, \mathrm{f}$ and $\mathrm{m}$ denote composite, fibre and matrix respectively. The assumptions underlying the rules of mixtures are not changed by the introduction of the FACF. 
Virk et al [2] reported experimental data for well-characterised quasi-unidirectional technical jute fibre reinforced epoxy resin matrix composites, manufactured by resin infusion under flexible tooling (RIFT) with a flow medium, and for the respective constituents. The experimental mean moduli and strengths were 8.19 $\pm 0.6 \mathrm{GPa}$ and 100.0 $\pm 5.7 \mathrm{MPa}$ respectively for dyed fibre/pigmented resin composites and 8.47 $\pm 1.18 \mathrm{GPa}$ and 101.0 $\pm 17.2 \mathrm{MPa}$ for undyed/unpigmented composites respectively (i.e. the difference between the pairs of respective mean values was $<50 \%$ of the lower standard deviation). The predicted modulus using Equation (1) without $\kappa$ was $6.44 \mathrm{GPa}(-24.0 \%$ from the experimental data for the undyed/unpigmented composites) and with $\kappa$ was 8.24 GPa $(-2.7 \%)$.

The experimental fibre strengths were analysed using natural logarithm interpolation (NLI) [4, 5], and multiple data set (MDS) weak link scaling (WLS) [6], models. The predicted strengths using Equation (2) without $\kappa$ were 79.2 MPa (NLIM, $-21.6 \%$ from the experimental data for the undyed/unpigmented composites) and 73.1 MPa (MDS, -25.4\%) and with $\kappa=1.42$ (2697/1896) were 102.9 (NLI, +1.9\%) and 95 MPa (MDS, -5.9\%) respectively (Figure 1).

Further, Virk et al [2] assumed that the FACF would be appropriate for other batches of jute fibres and analysed 14 sets of experiments conducted by other researchers with sliver, yarn, chopped strand or fabric reinforcements. The error in those predicted composite moduli was reduced when the FACF was used for all but two cases (Figure 2). Soatthiyanon et al [7] determined a fibre area correction factor of 2.70 for flax. By back-calculation from tensile tests on unidirectional composites, the modulus of the flax fibres was within $6 \%$, and the strength was within $7 \%$, of that for single fibre tests.

In conclusion, the modified generic RoM formulae do permit sensible prediction of the elastic moduli and strengths of NFRP, and hence address the challenge issued by Lau et al [1]. Further work is required to (a) determine the validity of the model for natural fibre composites from a broader range of sources, (b) establish if $\kappa$ varies with the range of "apparent" fibre diameters, (c) determine $\kappa$ for other natural fibres (and for non-circular [8] or hollow [9] synthetic fibres), and (d) confirm the validity of the new equations for a wider set of data. 


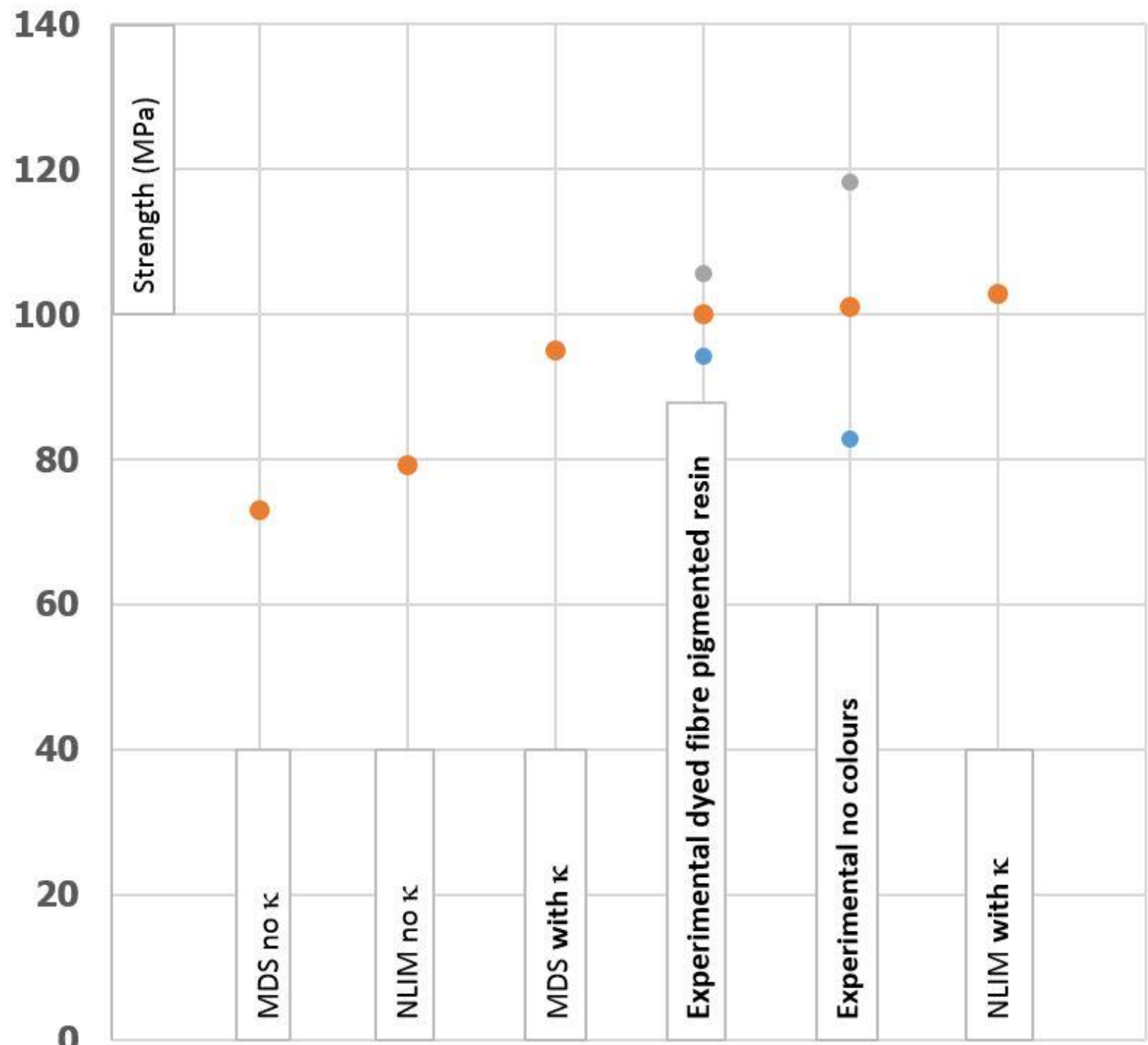

Figure 1: Strength of quasi-unidirectional jute/epoxy composites predicted using Equation 2 with and without the fibre area correction factor (FACF: $\kappa)$ compared to experimental values for materials with dyed fibres in pigmented resins or without colourants [2].

The experimental data points are the mean and \pm one standard deviation. 
Accepted for publication in Composites Part B: Engineering.

Available online 09 October 2018. https://doi.org/10.1016/j.compositesb.2018.10.021

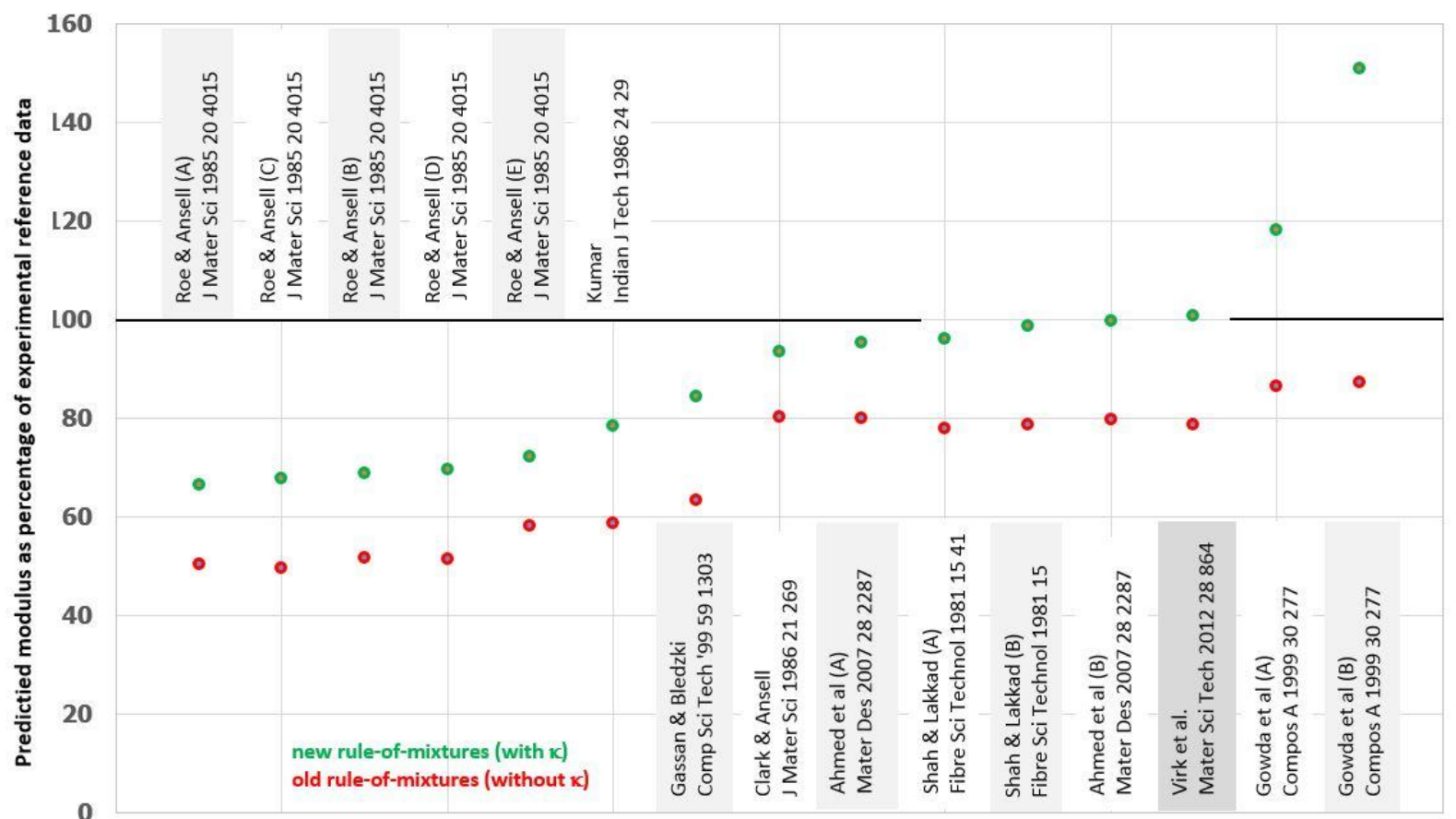

Figure 2: Comparison of rule-of-mixtures predicted moduli for jute fibre composites without (below/red) and with (above/green) the fibre area correction factor [2, 10-16]. 


\section{References:}

1. K.-t. Lau, P.-y. Hung, M.-H. Zhu and D. Hui, Properties of natural fibre composites for structural engineering applications, Composites Part B: Engineering, 1 March 2018, 136, 222-233.

2. A.S. Virk, W. Hall and J. Summerscales, Modulus and strength prediction for natural fibre composites, Materials Science and Technology, July 2012, 28(7), 864-871.

3. A. Kelly and W.R. Tyson, Tensile properties of fibre-reinforced metals: copper/tungsten and copper/molybdenum, Journal of the Mechanics and Physics of Solids, 1965, 13(6), 329-350.

4. A.S. Virk, W. Hall and J. Summerscales, Tensile properties of jute fibres, Mater. Sci. Technol., 2009, 25(10), 1289-1295.

5. A.S. Virk, W. Hall and J. Summerscales, Modelling tensile properties of jute fibres, Mater. Sci. Technol., 2011, 27(1), 458-460.

6. A.S. Virk, W. Hall and J. Summerscales, Multiple data set (MDS) weak-link scaling analysis of jute fibres, Composites Part A: Applied Science and Manufacturing, 2009, 40(11), 1764-1771.

7. N. Soatthiyanon, A. Crosky, and M.T. Heitzmann, Comparison of experimental and calculated tensile properties of flax fibres,

In D. Fernando, J.-G. Teng and J.L. Torero (editors), Proceedings of the Second International Conference on Performance-based and Life-cycle Structural Engineering (PLSE 2015), Brisbane QLD, Australia, 9-11 December 2015, 116-120.

8. S.J. Park, M.K. Seo and H.B. Shim, Effect of fiber shapes on physical characteristics of non-circular carbon fibers-reinforced composites, Materials Science and Engineering, 2003, A352(1-2), 34-39.

9. M Hucker, I.P. Bond, S. Bleay and S Haq, Experimental valuation of unidirectional hollow glass fibre (HGF)/epoxy composites under compressive loading, Composites Part A Applied Science and Manufacturing, 2003, 34(10), 927-932.

10. P. J. Roe and M. P. Ansell, Jute-reinforced polyester composites, Journal of Materials Science, 1985, 20(11), 4015-4020.

11. P Kumar, Mechanical behaviour of jute fibres and their composites, Indian Journal of Technology, 1986, 24(1), 29-32.

12. J Gassan and A K Bledzki, Possibilities for improving the mechanical properties of jute/epoxy composites by alkali treatment of fibres, Composites Science and Technology, 1999, 59(9), 1303-1309.

13. R. A. Clark and M. P. Ansell, Jute and glass fibre hybrid laminates, Journal of Materials Science, 1986, 21(1), 269-276.

14. K S Ahmed, S Vijayarangan and A C B Naidu, Elastic properties, notched strength and fracture criterion in untreated woven jute-glass fabric reinforced polyester hybrid composites, Materials and Design, 2007, 28 (8), 2287-2294.

15. A N Shah and S C Lakkad, Mechanical properties of jute-reinforced plastics, Fibre Science and Technology, 1981, 15 (1), 41-46.

16. T Munikenche Gowda, A C B Naidu and R Chhaya, Some mechanical properties of untreated jute fabric-reinforced polyester composites, Composites Part A: Applied Science and Manufacturing, 1999, 30 (3), 277-284.

\section{Supplementary information}

1: spreadsheet for modulus

2: spreadsheet for strength 